\title{
Scaring The Public: Fear Appeal Arguments In Public Health Reasoning
}

\section{LOUISE CUMMings}

\author{
School of Arts and Humanities \\ Nottingham Trent University \\ Clifton campus \\ Nottingham \\ Nottinghamshire, UK \\ louise.cummings@ntu.ac.uk
}

Résumé: L'étude des arguments qui font appel à la menace ou à la peur a donné naissance à une littérature abondante. Même dans un contexte de santé publique, on sait beaucoup comment employer ces arguments pour persuader le public de se conformer aux recommandations de santé. Malgré ce niveau d'intérêt pour ces arguments et l'examen de ceux-ci, ils ont un aspect qui reste encore inexploré. Cet aspect concerne la fonction heuristique de ces arguments au sein de notre réflexion sur des problèmes de santé publique. Plus précisément, je soutiens que les arguments qui font appel à la menace ou à la peur servent de raccourcis utiles dans nos raisonnements, en particulier lorsque que les raisonnements sont vulnérables à des préjugés qui vont probablement diminuer l'efficacité des messages de santé publique. Dans cette mesure, ces types d'arguments sont plutôt rationnellement justifiés que fallacieux, comme cela a été leur caractérisation dominante dans la logique

Key words: argumentum ad baculum; cognitive bias; fallacy; fear appeal argument; heuristics; public health

(C) Louise Cummings. Informal Logic, Vol. 32, No. 1 (2012), pp. 25-50. 


\section{Introduction}

Public health scientists face a number of challenges as they seek to protect the health of a population. They must transmit a message which is unpalatable to those whose behaviour the message is attempting to modify (e.g., people who smoke). They must couch this message in terms which are readily comprehensible to a public that is not well versed in scientific or medical matters. They must ensure that a message is sufficiently salient to compete with other messages, many of which involve issues that have greater immediacy for the public (e.g., choice of a mortgage versus the development of skin cancer 20 years henceforth). In all these areas, public health scientists are now guided by extensive academic literatures in disciplines such as health psychology, mass communication and the public understanding of science. In this paper, I want to present the case for another discipline, that of applied logic, to also play a role in the construction of public health messages. Specifically, it will be argued that a branch of logical inquiry known as informal logic contains a vast literature that has been almost completely overlooked by those whose role it is to devise and convey health advice to the public. This is in spite of the fact that many of the arguments that are the basis of this advice (e.g., argument from consequences) are vibrant areas of study within informal logic. In other publications, several of these arguments, including analogical argument, question-begging argument and the argument from ignorance, have been examined in public health contexts (Cummings, 2002, 2004, 2005, 2009, 2010, 2011). In this paper, a further argument, or rather group of arguments, which has been extensively investigated in informal logic, will also be examined in a public health context. Although known by various names, we will refer to these arguments as fear appeal arguments.

The long tradition in logic has been to view the arguments which will be examined in this paper as flaws or errors of reasoning. It is only in the last thirty to forty years that these socalled informal fallacies have been cast in a different, and more positive, light. When examined in certain contexts and evaluated against non-deductive standards, these arguments have been found to have non-fallacious variants. In this way, fallacy theorists have characterized non-fallacious forms of the argument from ignorance, question-begging argument and arguments that appeal to force, amongst others (Cummings, 2000; Walton, 1985, 1992; Woods, 1995, 2004). In the last couple of years, some fallacy theorists have gone a step further in their characterization of these argument forms by presenting them as reasoning heuristics (Cummings, 2010; Walton, 2010). In this way, 
Cummings (2010: 78) has represented certain informal fallacies as reasoning heuristics that "bestow epistemic gains on scientific inquiry in contexts of uncertainty." The scientific inquiry examined by Cummings was that conducted into the emergence of BSE in British cattle, a particularly protracted and difficult episode in the public health of the UK. ${ }^{1}$ For his part, Walton (2010: $160)$ proposes that "heuristics are closely connected to fallacies" and that heuristics are "a mediating concept between the notions of fallacy and defeasible argumentation scheme." We will return to Walton's views subsequently. In the meantime, we begin by examining the type of fear appeal argument that is the focus of this paper. This examination will include both its treatment in logic and in public health. We then consider how the notion of a heuristic has been employed in the literature on reasoning and informal fallacies. Finally, a new view is developed of the heuristic role of fear appeal arguments in a public health context.

\section{Arguments that threaten or appeal to fear}

Consider the following description of an anti-smoking video produced by the American Lung Association (1988). The video is entitled Hugh McCabe: The Coach's Final Lesson:

Mr. McCabe was a teacher and football coach in Montgomery County, Maryland. He had been a lifelong cigarette smoker. After being diagnosed with terminal lung cancer, he made arrangements for this film, his final legacy. The video documents, in detail, Mr. McCabe's decline. Viewers see Mr. McCabe go from an energetic man to a frail man whose hearty voice has become a whisper-the cancer has invaded his throat. Viewers watch as Mr. McCabe's doctor shows X-rays of his diseased lungs, and describes how he will die. They watch as Mr. McCabe expresses regrets about the experiences he will never have: He will never see his two sons graduate from high school, and he will never know his grandchildren. The final scene depicts Mr. McCabe's funeral and his coffin being carried out of a church. Throughout the video, $\mathrm{Mr}$. McCabe tells the viewers that cigarettes are the cause of

\footnotetext{
${ }^{1}$ Although the focus of the current paper is on the receiver of public health messages (i.e., members of the general public) rather than on the producer of these messages (i.e., public health experts), it is important to emphasize that many of the logical errors and cognitive biases that, I will argue subsequently, lay people are prone to making in their reasoning are also evident in the reasoning of the public health experts who issue health-related advice. Such errors and biases are analysed at length in Cummings (2010) in the context of a study of the reasoning of scientific experts in relation to the BSE problem.
} 
the cause of his lung cancer and that he would not have lung cancer if he were not a smoker (Schmitt and Blass, 2008: 147-8).

Schmitt and Blass (2008: 148) remark of this video "[a]lthough not theoretically conceived as a fear appeal, this videotape meets the definition of one. It presents a severe threat with fear-arousing consequences (lung cancer) that could have been avoided by taking the recommended response (not smoking)." These remarks touch on three issues which have made the characterization of fear appeal arguments difficult and contentious for theorists. The first of these issues concerns the relationship between fear and threat. As Schmitt and Blass describe this fear appeal, its purpose is to issue a threat with fear the (inevitable) consequence of this threat. We will see below that this particular characterisation of fear appeals is contested by some theorists. The second issue concerns the nature of fear appeals as a type of argument from consequence-Schmitt and Blass explicitly acknowledge the role of "consequences," in this case the development of lung cancer, as a key component in the structure of the argument. The third issue concerns the actions that could have been taken by the addressee of the fear appeal argument to avoid the undesirable consequence of developing lung cancer. In the social science literature on fear appeal arguments, these actions must display both self-efficacy (a person's belief that they can undertake the recommended action) and response efficacy (a person's belief that the recommended action will successfully avert the undesirable consequence) in order for a fear appeal argument to work. In addressing all three of these issues further below, we will be covering some of the main logical issues pertaining to fear appeal arguments as well as some of the social scientific literature on these arguments.

It is clear from the analysis of the above scenario presented by Schmitt and Blass that fear appeal arguments involve the issue of a threat to an addressee (this scenario formed the 'high-threat condition' in their experimental study of antismoking fear appeals). This threat then induces fear in a person which presumably acts as a trigger to modify one's behaviour in the recommended way. This close identification of threat with fear is commonplace in the public health literature on fear appeals. For Thompson et al. (2009: 182), the terms 'threat' and 'fear' are used interchangeably: "Our focus in this paper is on messages that are conveyed, and how anti-smoking campaigns, in particular, construct their appeals; with a specific focus on threat or fear-appeal campaigns." In other investigations, threat and fear are acknowledged to be distinct concepts which operate alongside each other in practice. For example, in a meta-analysis 
of fear appeal arguments in public health campaigns, Witte and Allen (2000: 592) state that "[w]hile fear and threat are conceptually distinct (the former is emotion, the latter is cognition), they are intricately and reciprocally related, such that the higher the perceived threat, the greater the fear experienced." In a study of the use of fear appeals in HIV prevention, Smerecnik and Ruiter (2010: 551) employ the notion of threat within their definition of a fear appeal: "A fear appeal combines threat information and coping information.... An individual is motivated to perform the recommended protective action only if a threat is perceived and if the recommended action is believed to be effective in averting the threat and easy to perform." Clearly, regardless of where one turns in the literature on the use of fear appeal arguments in public health, the notions of threat and fear are treated as essentially inseparable.

However, the situation is quite different when one comes to examine how fear appeal arguments have been addressed in logic. Walton (2000) gives an excellent account of the historical developments that saw the argumentum ad baculum move through a series of definitions beginning with appeal to force (the literal meaning is "argument to the stick"), then to the use of threat in argument and finally as an appeal to fear in argument. Perhaps surprisingly, there is no mention of an argument that corresponds to ad baculum in Aristotle's list of fallacies in On Sophistical Refutations, although Aristotle does discuss fear appeal arguments in Rhetoric (Walton, 2000). Ad baculum was consistently defined as an appeal to force up until the late 1940s when the notion of threat was used for the first time alongside force (Walton, 2000: 34). It was in 1956 that ad baculum came to be defined for the first time as an appeal to fear in argument as opposed to an appeal to force (Walton, 2000: 38). These transitions in the definition of the argument were ushered in by the publication of logic textbooks, certain of which presented examples that forced a reconsideration of earlier definitions of the argument. ${ }^{2}$ But what they demonstrate is that logicians have been much less inclined than investigators in public health and

\footnotetext{
${ }^{2}$ Walton (2000: 46) remarks of these textbooks as follows: "there is evidence of a certain degree of dissonance in the textbook treatments of the ad baculum. On the one hand, they maintained the traditional practice of describing the argumentum ad baculum as appealing to force, but the examples they gave are more subtle cases rather than overt or more brutal appeals to force. On the other hand, more and more elements of intimidation and indirect threats came to be present in the examples used to illustrate the fallacy. The headline or the primary heading described the argumentum ad baculum as being appeal to force. But in the descriptions of the argument given under that heading, typically the concept of threat was brought in, as it was in Copi, and the concept of appealing to fear was brought in, although in a lesser manner, as it was in Copi."
} 
social science to treat fear and threat appeals as one and the same type of argument. Walton (2000: 147-8) explicitly distinguishes fear and threat appeal arguments along the following lines: "a fear appeal argument is (necessarily) an intentional attempt by the speaker to frighten the hearer, whereas a threat appeal argument is not...the threat appeal argument and the fear appeal argument are inherently different. Neither is a subspecies of the other." It emerges that logicians observe certain conceptual distinctions in their treatment of these arguments that are either overlooked or conflated by social scientists.

The second issue raised by Schmitt and Blass's definition of fear appeal arguments concerns their nature as arguments from consequence. Walton (2000: 140) characterizes fear appeal arguments as a type of argument from negative consequence. This argument has the following structure:

If you (the respondent) bring about $\mathrm{A}$, then $\mathrm{B}$ will occur.

$B$ is a very bad outcome, from your (the respondent's) point of view (or interests).

Therefore, you (the respondent) should not bring about A.

Certain features of this argument are noteworthy, according to Walton. Firstly, this argument shares the same second premise and conclusion as the following argument, which Walton (2000: 140) calls a conditional baculum threat argument:

I (the proponent) undertake to see to it that $\mathrm{B}$ will occur if you (the respondent) bring about $\mathrm{A}$.

$\mathrm{B}$ is a very bad outcome, from your (the respondent's) point of view (or interests).

Therefore, you (the respondent) should not bring about A.

However, to the extent that Walton treats fear and threat appeals as two distinct types of argument, some way must be found of distinguishing these two arguments from negative consequence. That way lies in the first premises of these respective arguments. Only in the latter argument - the threat appeal - is the arguer indicating a commitment to undertake the negative consequence. In the former argument - the fear appeal-there is no explicit commitment of this type. As Walton remarks (2000: 141) "whether B comes about is up to nature - or at least there is no stipulation that any persistent agent stands ready to see to it personally that B will occur." So the distinction between fear and threat appeal arguments that is attested to by certain logicians, and largely overlooked by social scientists, now has a form in the logical structure of these arguments. Secondly, the conclusion of both these arguments is a practical ought (should) state- 
ment (Walton, 2000: 140). This reflects the fact that these arguments are a form of practical reasoning of the type that is used in deliberation and planning. This feature of these arguments is particularly significant when it comes to the question of their evaluation. It was described in Section 1 that many of the informal fallacies began to be characterized as non-fallacious when logicians began to assess them against non-deductive standards of argument. These same standards will be applied to the evaluation of fear appeal arguments in Section 4. Specifically, it will be argued that when assessed as a form of practical reasoning, fear appeals arguments are not just rationally warranted, but that they serve a faciltitative (heuristic) function within our reasoning.

The third issue raised by Schmitt and Blass's definition of a fear appeal argument - actions that can avert an undesirable consequence - brings us to a discussion of some of the findings that have emerged from social scientific research into fear appeal arguments. This research has revealed, for instance, that fear appeals are most effective, i.e., are most likely to induce behaviour change, when a strong fear appeal is combined with a high-efficacy message, and are least effective, i.e., likely to produce defensive responses, when strong fear appeals are combined with low-efficacy messages (Witte and Allen, 2000). Cognitive beliefs are known to act as mediators of fear appeal messages on intention. In a study of condom use in HIV prevention, Smerecnik and Ruiter (2010) found that anticipated regret (i.e., the expected post-behavioural affective consequences of not performing a behaviour that would keep one healthy) mediated the coping-intention relationship, with high coping information increasing anticipated regret which, in turn, increased the intention to use condoms. Fear appeals have also been found to elicit quite different responses in individuals in different stages of change. In a study of the effects of fear appeals that promoted skin cancer preventive behaviour, Cho and Salmon (2006) found greater defensive and fatalistic thinking in individuals who were in the precontemplation stage of change. These individuals were less receptive to message recommendations, displayed weaker intentions to engage in recommended behaviour and performed less preventive behaviour than those who had contemplated or previously undertaken preventive behaviour. Other findings indicate that personality traits or demographic characteristics such as gender do not appear to influence how fear appeals are processed, although there is evidence that the cultural orientation of respondents (i.e., individualist versus collectivist orientation) is a significant factor in the processing of these arguments (Murray-Johnson et al., 2001; Witte and Allen, 2000). 
Social scientists have also generated a number of theoretical models to explain these findings about the effects of fear appeal arguments. These models are the drive model (Janis, 1967), the parallel response model (Leventhal, 1970), the protection motivation model (Rogers, 1975) and a model that combines features of all three, the extended parallel process model (Witte, 1992). The drive model states that fear appeals arouse fear which acts as a drive to motivate actions. Fear has both facilitating (e.g., taking self-protective measures) and interfering (e.g., avoidance) effects according to this model. The model predicts that the more fear that is aroused the greater the attitude change. But this occurs only up to a point, after which individuals seek to reduce their fear by other means, such as not attending to the message. This model was abandoned when it became clear that the relationships predicted between fear arousal and attitude change were not supported by empirical findings. The parallel response model posits two separate but interdependent processes: danger control processes (those directed at reducing the danger) and fear control processes (those directed at reducing one's fear about the danger). These processes operate simultaneously (rather than sequentially) and permit subjects two quite different responses to fear appeals. Although this model introduced a cognitive component not present in the drive modelsubjects chose different responses and formed a plan of actionit failed due to its inability to predict the stimulus conditions that would cause subjects to choose one response or the other.

The protection motivation model develops the cognitive response to fear appeals further. Rogers's original and revised model identified the cognitive mediators that led to message acceptance. These so-called cognitive mediating processes included severity of threat, probability of occurrence, coping response efficacy and self-efficacy. Rogers proposed a four-way interaction between the dimensions of threat (severity and probability of occurrence) and efficacy (response efficacy and self-efficacy). The recipient of a fear appeal undertakes a rational calculation of the probability of certain outcomes (hence, the use of the term 'subjective expected utility' to describe these models). Although studies did not support Rogers's hypothesis, investigations have identified that one threat variable can interact with one efficacy variable to influence outcomes such as behaviour change. The final model, Witte's extended parallel process model (EPPM), proposes the following steps in the processing of fear appeals. A message is firstly evaluated for the threat that it contains. If the threat is perceived to be insignificant or irrelevant, then the fear appeal is simply ignored. If people believe there is a serious threat to which they are susceptible, then they are motivated to begin a second appraisal of the message. 
This second appraisal is an evaluation of the efficacy of the response that is recommended. When people believe the recommended action is effective in reducing the danger and that they are able to undertake this action (i.e., high perceived response efficacy combined with self-efficacy), then they become motivated to control the danger and lessen the threat. However, if people doubt their ability to undertake the recommended action (i.e., low perceived self-efficacy) and/or there is uncertainty that the action will actually work (i.e., low perceived response efficacy), they are motivated to control their fear through defensive responses such as denial (Witte and Allen, 2000). The predictions of this model have been tested in fear appeal campaigns designed to promote responsible drinking among college students and reduce the spread of genital warts (Moscato et al., 2001; Witte et al., 1998).

\section{Heuristics and reasoning}

The above discussion of fear appeal arguments is by no means exhaustive. However, it nevertheless conveys the main features of these arguments as they have been described and analyzed by logicians and social scientists. These two groups of theorists have contributed insights into fear appeal arguments that will be relevant to the view of these arguments developed in the next section. For their part, logicians have developed normative frameworks for the evaluation of fear appeals. These frameworks, many of which have a pragmatic orientation, are increasingly characterizing fear appeals as rationally warranted arguments in certain contexts of use. The view of fear appeals as cognitive heuristics, which will be developed in the next section, extends the more positive evaluations of these arguments that these frameworks have made possible. Social scientists have contributed to the study of fear appeal arguments an extensive understanding of the conditions under which people respond to, and ignore, the actions recommended by these arguments. Knowledge of these conditions will also be integral to the view of fear appeals as cognitive heuristics developed in Section 4. The convergence of logic and social science that my view of fear appeals entails will leave some readers uneasy. For logicians of a traditional bent, such a closely forged alliance raises the spectre of psychologism in logic. ${ }^{3}$ For their part, social sci-

\footnotetext{
3 I concur with the stance on psychologism taken by Gabbay and Woods (to appear) in their empirically sensitive logic: "Investigators who make room for context and agency are drawn to a form of what used to be called the Laws of Thought approach and, accordingly, are committed to an element of
} 


\section{Louise Cummings}

entists will be averse to the normative orientation of my view with its emphasis on the evaluation of reasoning. These objections reflect legitimate concerns by those who raise them. However, they can only be fully addressed in another context. For our present purposes, suffice it to say that the explanatory potential offered by a convergence of these disciplines far outweighs any difficulties raised by these objections.

So logical and social scientific considerations, I am claiming, must come together to forge the view of fear appeals as cognitive heuristics that is advanced in this paper. The notion of a heuristic has been employed in a range of domains, including computing, engineering and psychology. As such, definitions have tended to vary. In general, a heuristic is a type of shortcut through a problem that is beneficial to an agent in that it is economical with respect to cognitive effort and effective in achieving cognitive goals. Smithson (2008: 210) states that "at least some heuristics earn their keep by being not only fast and frugal, but also sufficiently accurate to be effective or adaptive." The idea that heuristics play a role in reasoning is certainly not new. Reasoning heuristics were first systematically studied by Amos Tversky and Daniel Kahneman. In their landmark article "Judgment under uncertainty: heuristics and biases," Tversky and Kahneman (1974: 1124) described a number of heuristics that reasoners use in probabilistic reasoning: "Many decisions are based on beliefs concerning the likelihood of uncertain events...people rely on a limited number of heuristic principles which reduce the complex tasks of assessing probabilities and predicting values to simpler judgmental operations." Although Tversky and Kahneman acknowledged that heuristics could be useful, they were concerned to emphasise the "severe and systematic errors" to which heuristics could lead. One such error is known as the gambler's fallacy, the belief that random processes self-correct: "if [a random] sequence has strayed from the population proportion, a corrective bias in the other direction is expected" (Tversky and Kahneman, 2004: 193).

By the time heuristics began to be discussed in the context of public health problems, an altogether more benign view of these cognitive operations was beginning to take shape. The emphasis now was less on the errors in reasoning to which heuristics might lead and more on their facilitative function in dealing with complex problems. Trumbo (2002) and Johnson (2005) discussed heuristics in two studies that applied a heuristic-

psychologism in logic...Psychologism is once again an open question in the research programme of logical theory. Its re-emergence should not be prejudged. Better to wait and see how, once it is up and running, a psychologically real, agent-based logic fares as a theory of reasoning" (italics in original). 
systematic model to the assessment of health risk. These studies required subjects to assess health risks that were communicated in epidemiological information about cancer rates (Trumbo) and which were posed by a semi-hypothetical industrial facility (Johnson). Johnson (2005: 632) states that

[a]...heuristic-systematic model (HSM) separate[s] sys-
tematic from heuristic information processing. The sys-
tematic approach...is deliberative, attends to detail,
weighs alternative views, and assesses argument quality
in judging the validity of persuasive messages. The heu-
ristic approach is alert to cues (e.g., trusted groups' eval-
uation of the information) and simple decision rules (if
encoded in memory, accessible to recall, and deemed
reliable) justifying quick intuitive judgment.

Factors which are likely to induce subjects to process information systematically or heuristically have also been examined in a public health context. Some of these factors relate to fear and threat. Kim and Paek (2009) found that a group of subjects motivated by accuracy were more likely to engage in systematic processing of information relating to the risks of GM food, while those motivated by impression were more likely to employ heuristic processing. Jepson and Chaiken (1990) found that subjects with high chronic fear of cancer were less likely to engage in systematic processing of messages than subjects with low fear. Subjects for whom a health message has high personal relevance have been found to engage in biased systematic processing, in which they are more critical of threatening parts of a message than parts of a message which they find reassuring (Liberman et al., 1992).

So, heuristics are not without precedent in the literature on reasoning or, indeed, in public health reasoning. But this literature has not so far addressed in a wholly convincing manner why heuristics are likely to be the dominant mode of reasoning in matters of public health. There are a number of reasons why this is likely to be the case. Firstly, systematic reasoning processes require subjects to make assessments of argument quality, a logical task in which the rational merits of different forms of evidence are considered. Yet, empirical studies suggest that subjects rarely engage with evidence sources in this manner. Instead, they are more likely to subscribe to a number of "rules of thumb" in assessing evidence, particularly when this evidence relates to an area that embodies expert knowledge. In a study of the public's understanding of food risks, Green et al. (2005: 525) remarked as follows: 
[F]ormal or 'scientific' sources of evidence were rarely cited to justify decisions about or assessments of food risks. This is not because participants were 'irrational' about potential risks, simply that, in making complex choices in an arena with considerable 'expert' information available, pragmatic decision aids are needed.

Commenting on a paper by Gjernes about Sami reindeer herders, Alaszewski and Coxon (2008: 418) state that:

She [Gjernes] notes that they [Sami herders] are aware of public health knowledge about health which is grounded in epidemiological evidence. Thus, they are aware of the health risk of smoking, not taking regular exercise and not eating vegetables and fruit. However, they filtered this advice through their traditional beliefs and practices developing particular forms of lay heuristics to guide their decisions.

While Sami herders are capable of subjecting epidemiological evidence to rational scrutiny, in their daily affairs they are more likely to adopt intuitive heuristics as a guide to decision-making.

Secondly, public health problems are uniquely challenging in terms of the impact of prior beliefs, attitudes and worldviews on subjects' responses to messages. These cognitive states are the basis of a number of biases in our thinking, biases which are likely to reduce compliance with the actions recommended in messages. One such bias is the optimistic bias, the belief that a subject's risk from a certain agent or behavior is less than that for the rest of the population (Weinstein, 1980, 1984). ${ }^{4}$ One can imagine how such a bias would reduce the effectiveness of many public health messages - for example, the subject who practices unprotected sex but who believes that he or she is at less risk of contracting HIV than everyone else who practices unprotected sex. Another bias in our thinking is the confirmatory bias, in which subjects interpret messages and events in line with their existing attitude position. ${ }^{5}$ This bias is likely to dimin-

${ }^{4}$ Weinstein characterizes this bias in the following terms: "They [people] expect others to be victims of misfortune, not themselves. Such ideas imply not merely a hopeful outlook on life, but an error in judgment that can be labeled unrealistic optimism" (1980: 806; italics in original); "A number of studies have shown that people's comparative risk judgments are optimistically biased; that is, they tend to think their own chances of experiencing health and safety problems are less than the chances of their peers" (1984: 431-2).

5 "People are exhibiting confirmatory bias when they (1) seek out and accept information that is consistent with their beliefs or biases, (2) ignore information that is not consistent with their beliefs or biases, or (3) interpret 
ish the force of many public health messages. In messages urging smoking cessation, for example, the public health communicator is trying to bring a respondent's beliefs about smoking in line with those expressed in the message. However, the confirmatory bias is pulling subjects in the opposite direction-the negative content expressed in the message about smoking is interpreted in line with the smoker's positive beliefs about smoking, thus reducing the likelihood that he or she will desist from smoking. Finally, there is evidence that in relation to health risks, subjects can assume a fatalistic worldview. ${ }^{6}$ To the extent that respondents believe they have very little control over risks to their health, they are unlikely to believe that they are capable of undertaking health-enhancing behaviours (i.e., self-efficacy) or that these behaviours will be effective in bringing about health improvements (i.e., response efficacy). Like cognitive biases, a fatalistic worldview is likely to reduce the effectiveness of public health messages.

Clearly, our thinking is influenced by a number of cognitive biases that are not conducive to the reception of public health messages. I contend that heuristics such as fear appeal arguments serve as a useful corrective to these biases. Specifically, heuristics enable us to bypass systematic reasoning processes that appear to be vulnerable to these biases and, in doing so, achieve a respondent's compliance with the actions recommended in public health messages. A well-crafted fear appeal argument, for example, seeks to counter the lack of self-efficacy and response efficacy that the cognitive mindset of fatalism engenders. A fear appeal argument with high threat content can serve as a valuable corrective to the optimistic bias - the person who believes that he or she is exposed to less health risk from a certain activity than other members of the population will struggle to uphold this thinking in the presence of strong fearprovoking images and descriptions. Even apart from cognitive biases, heuristics can help subjects to bypass systematic reasoning on other grounds. It is widely recognized that trust is an affective heuristic that allows subjects to bypass a lack of knowledge in systematic reasoning. In a study of trust and knowledge in the context of hazardous technologies and activities, Siegrist and Cvetkovich (2000) found strong correlations between social trust and perceived risks and benefits only when subjects did not possess much knowledge of the technologies concerned. Find-

information to support or confirm their beliefs or biases" (Covello, 2010: 1110).

${ }^{6}$ In the 1992 Canadian national health risk perception survey (Krewski et al., 1995), it was found that approximately half of respondents adopted a fatalistic worldview, with responses evenly split with respect to agreement with the statement "I have very little control over risks to my health." 
ings such as these have led investigators to the view that a range of emotional and affective processes serve a useful heuristic function in a range of contexts including public health. ${ }^{7}$ It is to an examination of the heuristic function of one emotion-based appeal, the appeal to fear, that we now turn.

\section{Fear appeal as a cognitive heuristic}

Thus far, I have argued that fear appeal arguments constitute heuristics that perform a useful corrective function to cognitive biases which can afflict systematic reasoning processes. Other heuristics based on trust, it was argued, helped subjects bypass a lack of knowledge during systematic reasoning. The view of heuristics that is taking shape in this paper is not one in which heuristic reasoning is a poor alternative to systematic reasoning which is only employed when logical considerations desert us. ${ }^{8}$ Rather, heuristic reasoning operates in parallel with systematic reasoning, ${ }^{9}$ a position from which it can shore up the more vulnerable logical processes of systematic reasoning. ${ }^{10}$ In this final

7 Thirlaway and Heggs (2005: 108) state that "emotion has been conceptualized as a heuristic, a mental shortcut, whereby people access their pool of positive and negative feelings towards an issue to guide judgement."

${ }^{8}$ Even theorists who take a positive view of the value of heuristics invariably end up characterizing them as inferior to the logical processes of systematic reasoning. For example, Walton (2010: 162) states that "[a] heuristic is only a shortcut, and if there is enough time for more evidence to be collected, a better method can often be found. The controlled, conscious and slow system of reasoning can pose critical questions, looking at evidential considerations pro and contra. An argument based on a heuristic might stand up or not under this more detailed kind of scrutiny." The italicized words in this quotation suggest that Walton is not prepared to afford to heuristics the value that he attaches to the "controlled, conscious and slow system of reasoning."

9 Social scientific research into fear appeal messages has tended to characterize the relationship between systematic and heuristic processing in antagonistic terms, i.e., messages are processed systematically or heuristically, but not both concurrently. A study by Hale et al. (1995) largely confirmed this pattern with low-fear message recipients engaging in systematic processing and high-fear message recipients engaging in heuristic processing. However, these investigators also found evidence of concurrent processing with low-anxiety subjects engaging in both systematic and heuristic processing of messages.

10 These processes are vulnerable in the sense of being the locus of cognitive biases and other problems (e.g., lack of knowledge). This vulnerability, I would argue, is related to the fact that systematic reasoning is a more recent development in terms of our cognitive evolution. Heuristic reasoning processes are part of an older evolutionary system and are more robust in nature. They owe their robustness to evolutionary pressures exerted on our cognitive resources over many years. This view is consistent with dualprocess theories of reasoning and cognition, as Walton (2010: 161) 
section, I want to develop further this view of heuristics, and fear appeal argument in particular, as an adjuvant to logical reasoning, contra those theorists who treat heuristics as a less reliable alternative to logical reasoning. Through their capacity to avert biases and other pitfalls of logical reasoning, heuristics assume a rational standing in this account that has seldom been properly acknowledged by theorists of reasoning. How to characterize that standing is the second task of this section. Only one theorist, Douglas Walton, has so far attempted to give an account of the rational standing as heuristics of the types of arguments within which fear appeals are routinely included, the socalled informal fallacies. According to Walton (2010), heuristics involve jumping to a conclusion with such jumps overlooking prerequisites of a defeasible argumentation scheme for a certain type of argument. It will be shown subsequently that this account is not wholly satisfactory for the view of fallacies as heuristics that is developed in this paper. We conclude with a suggestion for how these heuristics might be better captured.

In his account of fear appeal argument, Walton (2000) discusses a television commercial that conveys a message against drinking and driving. The content of the commercial will be familiar to television viewers. A boy causes the death of his girlfriend through drunk driving. He is pictured in a distressed state pleading with paramedics to be allowed to accompany her in the ambulance to hospital. A police officer is shown breaking the news of the girl's death to her parents. Walton (2000: 9) follows a description of the commercial with the following comments:

Is it fair or reasonable to categorize such an ad as a fallacious fear appeal argument (ad metum), because the argument appeals to emotion instead of presenting evidence (in the form of statistics on fatalities and drunk driving, for example)?

It was described in Section 3 how evidence did not always enter into an assessment of health-related risks in ways that we might expect if people were driven by logical considerations. In that section, subjects who undertook assessments of food-related risks were shown to disregard scientific sources of evidence in favour of "pragmatic decision aids." Also, Sami reindeer herders, it was argued, could assess epidemiological evidence about

acknowledges: "According to dual process theories in cognitive science, there are two distinct cognitive systems underlying human reasoning. One is an evolutionarily old system that is associative, automatic, unconscious, parallel, and fast.... The other is a system that is rule-based, controlled, conscious, serial, and slow.... The old system uses what are called heuristics to rapidly jump to a conclusion or course of action." 
about health-related risks, but were much more likely to use "lay heuristics" in making assessments of these risks. What these cases demonstrate is that systematic reasoning processes, in which people carefully reflect on sources of evidence in a rational evaluation of argument, is something of an idealization of the logical performance of subjects. While subjects may, on occasion, engage with evidence in this manner, more often than not they are inadequately equipped or motivated to do so. There is no clearer example of how our logical performance deviates from this ideal than when subjects come to assess the type of statistical evidence mentioned above by Walton. In the present scenario, this evidence will describe the (increased) likelihood or probability of a fatal car accident occurring if one drinks and drives. The problem is that an assessment of this evidence requires subjects to engage with probabilistic information when a long list of empirical studies beginning with Tversky and Kahneman's now classic experiments indicate that this is a rather weak area of logical performance. Berry (2004: 27) captures our difficulties in this area when she states that:

[T] here is now a firm body of evidence showing that many people are subject to various cognitive difficulties when interpreting probabilistic information. Furthermore, we are all prone to a range of cognitive biases, and our interpretation of risk information is often influenced by the particular way in which it is presented to us.

Berry presents an excellent overview of empirical work in this area. She discusses experimental findings which indicate that people have difficulty interpreting percentages (for this reason, health messages often present probabilities as frequencies rather than as percentages), that people prefer to use verbal probability expressions (e.g., "likely," "rare") over numbers to convey risks (but prefer to be given numerical probabilities in risk information), and that context influences how people interpret percentages and verbal probability labels. She also describes how judgements are excessively influenced by the total number of people who are adversely affected by a drug, etc. (there is insufficient consideration of the size of the overall sample in a particular case) and how relative risk reductions have a greater impact on health behaviours than information which is expressed as absolute risk reductions. If we add to these specific difficulties with probabilistic information a number of cognitive biases, such as the optimistic bias and confirmatory bias, the picture that emerges is a fairly gloomy one about our prospects for successfully handling the statistical evidence to which Walton refers. The question now is that if viewers of 
this television commercial are unlikely to be able to use logical processes of reasoning in an assessment of the risks posed by drinking and driving, what other cognitive resources can be successfully exploited by the producers of the commercial to dissuade viewers from engaging in this potentially injurious behaviour? The answer is fear appeal argument used as a cognitive heuristic.

The producers of the drinking and driving commercial, I am claiming, have little prospect of achieving their goal of reducing this behaviour if they develop a message that viewers must process using logical, systematic reasoning. So prone is this form of reasoning to a range of errors and cognitive biases that it is best avoided, particularly on those occasions when the human costs of not successfully communicating a message are great. The public health communicator should aim to engage the recipients of a message in heuristic reasoning. This reasoning is not only as accurate as more systematic processes of reasoning $^{11}$ — at least on a sufficiently large number of occasions - but it also provides subjects with a means of bypassing potentially erroneous logical processes. (Of course, this is not to say that heuristic reasoning is guaranteed to eliminate logical or other errors of reasoning. Moreover, as demonstrated in Cummings (2010), heuristics can themselves be sources of error when they are misapplied in a certain context.) With its roots in an older cognitive system, heuristic reasoning has been shaped by evolutionary pressures which have better prepared it to withstand the types of errors to which systematic reasoning so readily succumbs. Some of these errors stem from the additional complexity of systematic processes. This complexity, which is eschewed by heuristics, introduces a greater number of opportunities for error to occur-put quite simply, there are more things that can go wrong. By embodying simplicity, heuristics reduce the likelihood of error. To cite Todd and Gigerenzer (2000: 727), their "simplicity leads to robustness." When used as a cognitive heuristic, fear appeal argument is directly availing of the benefits that have been accrued by heuristic reasoning as a result of its adaptations to evolutionary pressures over many years. These benefits mean that fear appeal argument can

\footnotetext{
${ }^{11}$ Quite apart from being less accurate than systematic reasoning processes, simple heuristics have been found to perform comparably to more complex algorithms: "[W]e show how simple building blocks that control information search, stop search, and make decisions can be put together to form classes of heuristics, including: ignorance-based and one-reason decision making for choice, elimination models for categorization, and satisficing heuristics for sequential search. These simple heuristics perform comparably to more complex algorithms, particularly when generalizing to new data" (Todd and Gigerenzer, 2000: 727).
} 
achieve results for the public health communicator that are less likely to be realised by systematic reasoning. The results of interest are intention change and behaviour modification. We examine this point further below.

To the extent that a fear appeal argument is attempting to influence the actions of subjects, it is a type of practical reasoning. In effect, the aim of the public health communicator is to encourage recipients of a message to choose one course of action (e.g., the cessation of smoking) over another course of action (e.g., the continuation of smoking). The action-oriented nature of practical reasoning sets in place normative standards for the evaluation of reasoning which are very different from those that apply in theoretical contexts. For example, in practical reasoning a cognitive agent must consider temporal aspects of his or her situation in a way that the person who is engaged in theoretical reasoning can largely disregard. Similarly, in practical reasoning a cognitive agent must make an assessment of the urgency of his or her situation, as decisions quite often must be taken in advance of complete knowledge of a health risk. In practical reasoning, agents must assess the consequences of particular courses of action, some of which may be very grave indeed. These various exigencies of the practical sphere can be seen throughout public health. Many public health issues are defined by temporal considerations, such as the length of exposure to a health risk. Public health actions are routinely taken in advance of full knowledge of a health risk, such as when quarantine measures are introduced to control the spread of a newly emerging infectious disease. Also, the consequences of not undertaking public health actions, or undertaking the wrong actions, are often quite serious in terms of their toll on human health and well-being. Fear appeal argument is uniquely placed to address these practical imperatives. It is able to do so, I contend, because it is highly adapted to the exigencies of the practical sphere in a way that other modes of reasoning are not.

Fear is a powerful emotion that can move people to action. But it is the particular way in which it does this that makes fear appeal argument so effective as a heuristic. Above, it was described how fear appeal argument bypasses systematic processes of reasoning which are prone to error and biases. This same capacity to bypass these processes is what makes fear appeal argument so well attuned to features of the practical sphere. In its careful consideration of evidence in an assessment of argument quality, systematic reasoning is slow and time consuming. By bypassing these processes, fear appeal argument can help subjects come to judgement on a problem with a speed that is more in keeping with the temporal demands of their context. Also, by bypassing extensive deliberations surrounding evidence in sys- 
tematic reasoning, fear appeal argument can jump straight to decisions about which courses of action to pursue. This satisfies the practical imperative in public health in particular to institute protective actions in advance of full evidence and knowledge about a health risk. Finally, by bypassing systematic reasoning processes, we avoid the suppression of fear-systematic processes, after all, achieve the subordination of emotional factors to logical considerations. Fear appeal argument unambiguously confronts us with a particularly unpleasant consequence of not pursuing a recommended course of action-we will continue to experience fear. Of course, we may deflect that fear by engaging in defensive reactions such as denial. But even the very threat of such prolonged psychological discomfort may be all that is required to achieve compliance with certain recommended behaviours. It emerges that as well as being an important corrective to logical errors and cognitive biases in systematic reasoning, fear appeal argument is well equipped to address the demands of the practical sphere.

The practical orientation of fear appeal arguments has implications for whatever normative framework we choose to capture the rational features of these arguments. Clearly, this framework cannot be based on deductive notions of validity and soundness, i.e., the logical standard embodied by systematic reasoning processes. Rather, fear appeal argument demands a normative model that attests to a range of pragmatic features, such as temporal features of context, the urgency of deliberation, and the consequences of action and inaction. For Walton (2010: 164), that model consists in a defeasible argumentation scheme which is the focus of critical questions: "This scheme is defeasible. It is not deductively valid.... Such a defeasible scheme is inherently subject to critical questioning." These questions are modelled via assumptions and exceptions (both types of premises) that are added to the explicit premises in the full scheme of the argument. Assumptions and exceptions may be taken to represent responses to questions that aim to lay bare the rational grounds of a particular argument. For example, in the case of the argument from expert opinion (see Figure 1), an assumption to the effect that an individual $E$ is an expert in the field to which claim $A$ belongs is central to the rational standing of this argument. A parascheme, which models the heuristic that corresponds to the full scheme, overlooks these assumptions and exceptions. This can be seen in Figure 1 below where the heuristic jumps to a conclusion ("A is true") on the basis of just two ordinary premises without taking into account any of the assumptions and exceptions: 


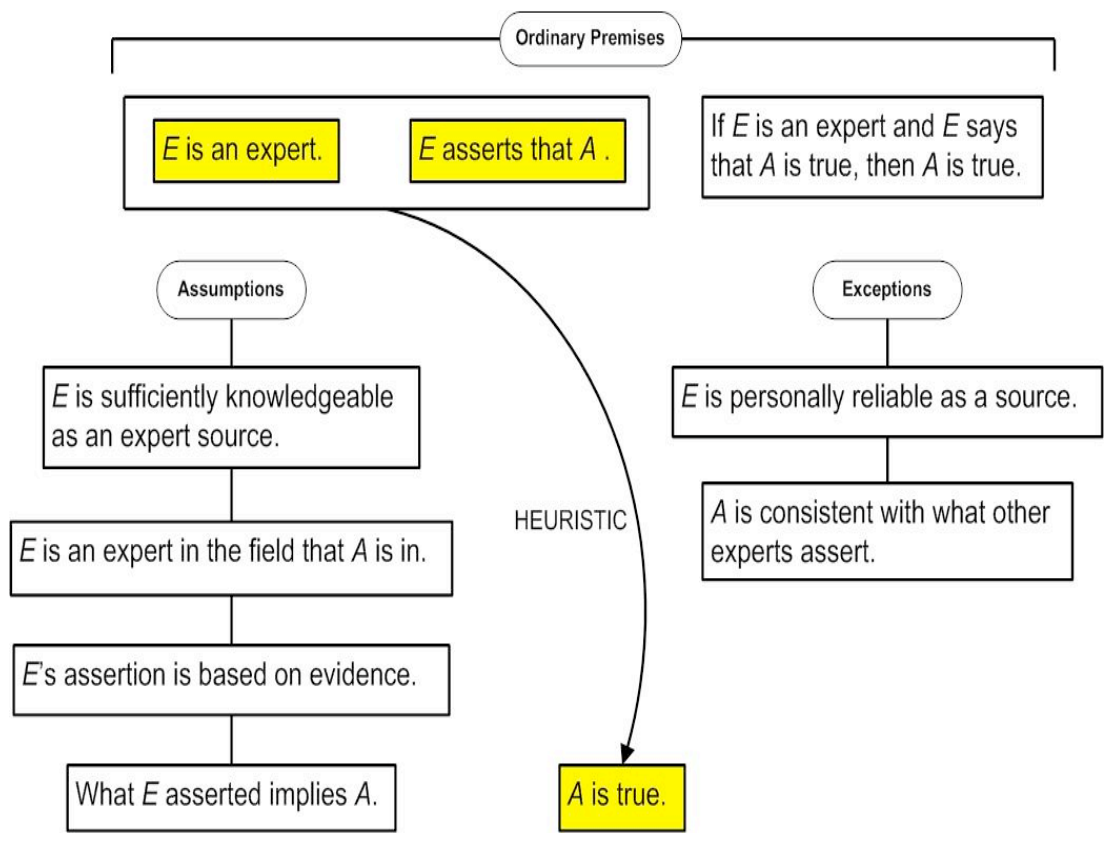

Figure 1: Heuristic of Argument from Expert Opinion, taken from Walton (2010: 170)

Walton (2010: 171) characterizes the particular heuristic represented in Figure 1, the heuristic of argument from expert opinion, as taking us by a "fast and frugal leap directly to the conclusion." In so doing, it bypasses the implicit conditional premise in the top right corner of the above diagram, as well as the assumptions and exceptions. The consideration of these additional factors requires processing time that is only afforded by the "controlled, conscious, and slow inferential procedure of the new cognitive system." The old cognitive system of reasoning, which is the home of heuristic procedures, sacrifices this additional deliberation with a view to achieving certain efficiencies, such as an increase in the speed of processing.

Walton (2010: 175) envisages a similar parascheme as the basis for the heuristic relating to fear appeal argument: "Especially the emotional fallacies like appeal to fear seem to be based on heuristics that would respond well to paraschematic treatment." Like the argument from expert opinion above, the heuristic corresponding to a fear appeal argument involves leaping to a conclusion, usually to take a certain course of action, without consideration of a range of conditions which might make such a course of action ill-advised in a particular case:

Fear is an emotion that moves people powerfully to action and may tend to make them put more careful considerations of the complex features of a situation aside. 
An immediate response may be to jump to a conclusion, powerfully motivated by fear, instead of taking a more realistic look at all the factors involved in a decision. The heuristic for this kind of reasoning runs as follows. If I carry out action $\alpha$, it may bring about consequence $C$. Consequence $C$ is really scary. Therefore, there is no way I am going to bring about action $\alpha$ (Walton, 2010: 178).

However, I want to argue that there are reasons for believing that a parascheme is not completely adequate as a model of the factors that are at work in fear appeal argument used as a heuristic. According to Walton's account, a parascheme is derivative upon the full scheme for an argument, from which it stakes its claim to rational justification. So the heuristic that is modelled by a parascheme is rationally justified, at least on certain occasions, because it draws upon an argumentation scheme in which explicit premises and (implicit) assumptions and exceptions are the outcome of critical questioning. The difficulty with this arrangement is that it reverses what is, I believe, the correct relationship between a full argumentation scheme and its corresponding parascheme. As Walton acknowledges, heuristics are part of an "old cognitive system" which is prior, in evolutionary terms, to the systematic reasoning processes of the new cognitive system. Walton's full argumentation schemes are part of this new cognitive system. As such, I contend, they cannot precede paraschemes, as Walton's characterization would have it. Full argumentation schemes are a later evolutionary achievement and are, accordingly, emergent upon the heuristic reasoning processes that Walton is modelling as paraschemes. We should think of full argumentation schemes as an exercise in theoretical rationality in which the complete grounds of an argument are laid bare. But what precedes these schemes-what they are, in effect, a development or expansion of - is a type of rapid, simplistic reasoning in the form of heuristics.

Evolutionary considerations, it emerges, necessitate a reversal in the relationship between Walton's full argumentation schemes and paraschemes. This reversal is further necessitated by the conditions that provide a rational justification of the heuristic reasoning in paraschemes. For Walton, this reasoning derives its rational standing from the full argumentation scheme which sits alongside the parascheme. In the full scheme, all implicit premises of an argument are laid bare as a result of critical questioning. The explicit argument which emerges from this critical questioning is presumed to justify the corresponding heuristic. I believe Walton's characterization of the relationship between a full argumentation scheme and a parascheme misrepresents the conditions that provide a rational justification of heu- 
ristic reasoning. If a parascheme is derivative upon a full argumentation scheme, as Walton claims is the case, then it can seem as if conditions laid out in the full scheme do indeed justify the heuristic reasoning of the parascheme. But if, as I am arguing, heuristic reasoning is justified by conditions in the practical sphere, then we must once again adopt a different view of the relationship between a full argumentation scheme and parascheme. Specifically, heuristic reasoning has arisen to address practical exigencies within our environment, e.g., the need to respond with urgency to problems. To this extent, heuristics may be seen to be an evolutionary adaptation to conditions in the practical sphere. It is these conditions, I contend, that ultimately provide a rational justification of the different patterns of reasoning that we have been describing in this paper as heuristics. In casting a parascheme as dependent on a full scheme for its rational justification, Walton loses sight of the practical rationality that ultimately justifies heuristic reasoning.

In summary, I have argued that heuristic reasoning is an evolutionary adaptation to certain practical conditions that confront cognitive agents within their environment. It is these conditions of the practical sphere that provide a rational justification of the rapid, efficient cognitive procedures that we have been calling heuristics. However, with the evolution of higher-order cognitive abilities, human beings have developed the capacity to expand heuristics into longer, detailed logical structures of the type we have been calling systematic reasoning. Where heuristic reasoning aims for simplicity and speed, systematic reasoning embodies complexity and slowed processing. To the extent that heuristics are justified on practical grounds and systematic reasoning is a later evolutionary development than heuristic reasoning, I have argued for a revision of Walton's parascheme model of heuristics. Specifically, I have contended that paraschemes are prior to full argumentation schemes in both evolutionary and conceptual terms, and are not derivative upon them, as Walton's model would have it. The primacy of heuristic reasoning, and parascheme models thereof, is not an explanatory convenience. Rather, this arrangement is needed in order to locate fear appeal arguments and other heuristics within the type of practical rationality that is their evolutionary origin.

Acknowledgements: The author wishes to acknowledge with gratitude the comments of two reviewers of Informal Logic on an earlier version of this paper. 


\section{References}

Alaszewski, A. and Coxon, K. (2008). "The everyday experience of living with risk and uncertainty." Health, Risk \& Society, 10 (5): 413-420.

American Lung Association. (1988). Hugh McCabe: The Coach's Final Lesson. Santa Monica, CA: Pyramid Media.

Berry, D. (2004). Risk, Communication and Health Psychology, Milton Keynes: Open University Press.

Cho, H. and Salmon, C.T. (2006). "Fear appeals for individuals in different stages of change: Intended and unintended effects and implications on public health campaigns." Health Communication, 20(1): 91-99.

Covello, V.T. (2010). "Risk communication." In H. Frumkin (Ed.) Environmental Health: From Global to Local, pp. 1099-1140. San Francisco: John Wiley \& Sons.

Cummings, L. (2000). "Petitio principii: The case for nonfallaciousness." Informal Logic, 20(1): 1-18.

Cummings, L. (2002). "Reasoning under uncertainty: The role of two informal fallacies in an emerging scientific inquiry." Informal Logic, 22(2): 113-136.

Cummings, L. (2004). "Analogical reasoning as a tool of epidemiological investigation." Argumentation, 18(4): 427-444.

Cummings, L. (2005). "Giving science a bad name: Politically and commercially motivated fallacies in BSE inquiry." Argumentation, 19(2): 123-143.

Cummings, L. (2009). "Emerging infectious diseases: Coping with uncertainty." Argumentation, 23(2): 171-188.

Cummings, L. (2010). Rethinking the BSE Crisis: A Study of Scientific Reasoning under Uncertainty. Dordrecht: Springer.

Cummings, L. (2011). "Considering risk assessment up close: The case of bovine spongiform encephalopathy." Health, Risk \& Society, 13(3): 255-275.

Gabbay, D.M. and Woods, J. (to appear). Seductions and Shortcuts: Fallacies in the Cognitive Economy. North Holland: Elsevier.

Green, J.M., Draper, A.K., Dowler, E.A., Fele, G., Hagenhoff, V., Rusanen, M. and Rusanen, T. (2005). "Public understanding of food risks in four European countries: A qualitative study." European Journal of Public Health, 15(5): 523-527.

Hale, J.L., Lemieux, R. and Mongeau, P.A. (1995). "Cognitive processing of fear-arousing message content." Communication Research, 22(4): 459-474.

Janis, I.L. (1967). "Effects of fear arousal on attitude change: Recent developments in theory and experimental research." In L. Berkowitz (Ed.), Advances in Experimental Social Psychology, Vol. 3, pp. 166-225. New York: Academic Press. 
Jepson, C. and Chaiken, S. (1990). "Chronic issue-specific fear inhibits systematic processing of persuasive communications." Journal of Social Behavior and Personality, 5(2): 6184.

Johnson, B.B. (2005). "Testing and expanding a model of cognitive processing of risk information." Risk Analysis, 25(3): 631-650.

Kim, J. and Paek, H.-J. (2009). "Information processing of genetically modified food messages under different motives: An adaptation of the multiple-motive heuristic-systematic model." Risk Analysis, 29 (12): 1793-1806.

Krewski, D., Slovic, P., Bartlett, S., Flynn, J. and Mertz, C. (1995). "Health risk perception in Canada II: Worldviews, attitudes and opinions." Human and Ecological Risk Assessment, 1 (3): 231-248.

Leventhal, H. (1970). "Findings and theory in the study of fear communications." In L. Berkowitz (Ed.), Advances in Experimental Social Psychology, Vol. 5, pp. 119-186. New York: Academic Press.

Liberman, A. and Chaiken, S. (1992). "Defensive processing of personally relevant health messages." Personality and Social Psychology Bulletin, 18(6): 669-679.

Moscato, S., Black, D.R., Blue, C.L., Mattson, M., Galer-Unti, R.A. and Coster, D.C. (2001). "Evaluating a fear appeal message to reduce alcohol use among 'Greeks'." American Journal of Health Behavior, 25(5): 481-491.

Murray-Johnson, L., Witte, K., Liu, W.-Y., Hubbell, A.P., Sampson, J. and Morrison, K. (2001). "Addressing cultural orientations in fear appeals: Promoting AIDS-protective behaviors among Mexican immigrant and African American adolescents and American and Taiwanese college students." Journal of Health Communication, 6(4): 335-358.

Rogers, R.W. (1975). "A protection motivation theory of fear appeals and attitude change." Journal of Psychology, 91: 93114.

Schmitt, C.L. and Blass, T. (2008). "Fear appeals revisited: Testing a unique anti-smoking film." Current Psychology, 27(2): 145-151.

Siegrist, M. and Cvetkovich, G. (2000). "Perception of hazards: The role of social trust and knowledge." Risk Analysis, 20 (5): 713-720.

Smerecnik, C.M.R. and Ruiter, R.A.C. (2010). "Fear appeals in HIV prevention: The role of anticipated regret." Psychology, Health \& Medicine, 15(5): 550-559.

Smithson, M. (2008). "Psychology's ambivalent view of uncertainty." In G. Bammer \& M. Smithson (Eds.), Uncertainty 
and Risk: Multidisciplinary Perspectives, pp. 205-217. London: Earthscan.

Thompson, L.E., Barnett, J.R. and Pearce, J.R. (2009). "Scared straight? Fear-appeal anti-smoking campaigns, risk, selfefficacy and addiction." Health, Risk \& Society, 11(2): 181196.

Thirlaway, K.J. and Heggs, D.A. (2005). "Interpreting risk messages: Women's responses to a health story." Health, Risk \& Society, 7(2): 107-121.

Todd, P.M. and Gigerenzer, G. (2000). "Simple heuristics that make us smart." Behavioral and Brain Sciences, 23(5): 727741.

Trumbo, C.W. (2002). "Information processing and risk perception: An adaptation of the heuristic-systematic model." Journal of Communication, 52(2): 367-382.

Tversky, A. and Kahneman, D. (1974). "Judgement under uncertainty: Heuristics and biases.” Science, 185(4157): 11241131.

Tversky, A. and Kahneman, D. (2004). "Belief in the law of small numbers." In E. Shafir (Ed.), Preference, Belief and Similarity: Selected Writings by Amos Tversky, pp. 193-202. Cambridge, MA: The MIT Press.

Walton, D.N. (1985). "Are circular arguments necessarily vicious?" American Philosophical Quarterly, 22(4): 263-274.

Walton, D.N. (1992). "Nonfallacious arguments from ignorance." American Philosophical Quarterly, 29(4): 381-387.

Walton, D.N. (2000). Scare Tactics: Arguments that Appeal to Fear and Threats. Dordrecht: Kluwer Academic Publishers.

Walton, D.N. (2010). "Why fallacies appear to be better arguments than they are." Informal Logic, 30(2): 159-184.

Weinstein, N.D. (1980). "Unrealistic optimism about future life events." Journal of Personality and Social Psychology, 39(5): 806-820.

Weinstein, N.D. (1984). "Why it won't happen to me: Perceptions of risk factors and susceptibility." Health Psychology, 3(5): 431-457.

Witte, K. (1992). "Putting the fear back into fear appeals: The extended parallel process model." Communication Monographs, 59: 329-349.

Witte, K. and Allen, M. (2000). "A meta-analysis of fear appeals: Implications for effective public health campaigns." Health Education \& Behavior, 27(5): 591-615.

Witte, K., Berkowitz, J.M., Cameron, K.A. and McKeon, J.K. (1998). "Preventing the spread of genital warts: Using fear appeals to promote self-protective behaviors." Health Education \& Behavior, 25(5): 571-585. 
50 Louise Cummings

Woods, J. (1995). “Appeal to force." In H.V. Hansen \& R.C. Pinto (Eds.), Fallacies: Classical and Contemporary Readings, pp. 240-250. Pennsylvania: The Pennsylvania State University Press.

Woods, J. (2004). The Death of Argument: Fallacies in AgentBased Reasoning. Dordrecht: Kluwer Academic Publishers. 